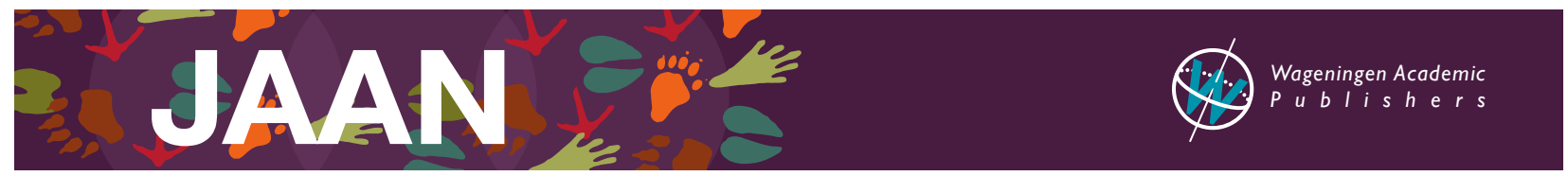

\title{
Effect of a novel fermented soy product on gastric ulcer scores in horses
}

\author{
S.L. Raidal" and K.J. Hughes \\ Charles Sturt University, School of Animal and Veterinary Sciences, Boorooma St, Wagga Wagga, NSW 2650, Australia; \\ sraidal@csu.edu.au
}

Received: 14 June 2020 / Accepted: 13 July 2020

(c) 2020 S.L. Raidal and K.J. Hughes

RESEARCH ARTICLE

EQUINE

\begin{abstract}
Non-pharmaceutical methods are desirable to treat or prevent gastric ulceration in horses. This two-period, randomised, double-blinded placebo-controlled study was designed to evaluate the efficacy of dietary supplementation ( $25 \mathrm{~g}$ once daily in feed for 30 days) with Fermaid ${ }^{\circ}$ Ease 187 (FE, Lallemand Australia Pty Ltd, Maroochydore, Australia) on gastric squamous and glandular mucosal ulcer scores in horses. Gastroscopy of 120 horses presented to the Veterinary Clinical Centre at Charles Sturt University (CSU; Bathurst, Australia) or at local training establishments identified 60 horses with spontaneous gastric ulcer disease (50\%). Of horses eligible for inclusion, 29 horses were recruited and randomised to receive either the $\mathrm{FE}$ or placebo for 30 days. Effects were assessed by repeat gastroscopy (Day 31), at which time horses started the reciprocal treatment. Eleven horses successfully completed both treatment periods. Treatment with FE showed a significant decrease in squamous ulcer scores in period $1(P=0.008)$, with a similar effect observed in period 2. No change was observed in squamous ulcer scores for horses receiving placebo treatment in period 1, but increased squamous scores were observed in horses receiving placebo treatment in period $2(P=0.062)$. Squamous ulcer scores on Day 31 were significantly lower $(P=0.005)$ following FE treatment than for horses receiving the placebo treatment. No effects were observed on glandular ulcer scores. This study supported the use of FE in horses predisposed to ulceration of the squamous gastric mucosa.
\end{abstract}

Keywords: equine gastric ulcer syndrome, lecithin, probiotics, lactic acid bacteria

\section{Introduction}

Equine gastric ulcer syndrome (EGUS) is a common problem in both foals and adult horses, and may present with symptoms including colic, inappetence, ill thrift, hair coat changes, poor performance, behaviour changes and stereotypies (Lester et al., 2008; Malmkvist et al., 2012; Nicol et al., 2002; Sykes and Jokisalo 2014). The condition encompasses erosive and ulcerative conditions of the squamous and glandular mucosa, now termed equine squamous gastric disease (ESGD) and equine glandular gastric disease (EGGD), respectively (Sykes et al., 2015). The development of gastric ulceration may be viewed as an imbalance between mucosal effects of aggressive and protective factors, with ulceration of squamous and glandular mucosa representing different disease entities with distinct pathophysiology (Sykes and Jokisalo, 2014). Horses secrete gastric acid continuously in the stomach, and exposure to acid and other digestive factors is considered the major risk factor for development of ulceration in the squamous mucosa (Nadeau et al., 2003a,b). Risk factors for ESGD include stress, high grain diets and intense exercise, whilst the use of non-steroidal anti-inflammatory drugs has been linked to EGGD (Lester et al., 2008; Videla and Andrews, 2009). Squamous lesions have been reported in over $80 \%$ of horses in race training (Begg and O'Sullivan, 2003, Murray et al., 1996), however, ESGD has been equally recognised in performance horses (Hartmann and Frankeny, 2003; McClure et al., 1999), endurance horses (Tamzali et al., 2011) and broodmares (Le Jeune et al., 2009). The prevalence of EGGD has been less extensively characterised (Sykes et al., 2015). 
Pharmaceutical treatment options are effective in reducing the prevalence and severity of gastric ulceration (Orsini et al., 2003; Stothert et al., 1980) by suppressing gastric acid secretion and/or protecting the mucosa. Histamine receptor antagonists, such as ranitidine, or proton-pump inhibitors, such as omeprazole, are widely used for the treatment and/or prevention of EGUS in horses, but must typically be administered continuously when horses are in work. Although effective for the treatment or prevention of ESGD, proton-pump inhibitors are not curative, and relapse is common when treatment is discontinued (Andrews et al., 2006). Ulceration of glandular mucosa, although less common than squamous ulceration, appears more refractory to medical management (Sykes and Jokisalo, 2015a), and concern has been expressed that a prolonged increase in gastric $\mathrm{pH}$ might affect gastrointestinal microbiota (Jackson et al., 2016), gastric physiology and digestion (Andrews et al., 2016). Non-pharmaceutical agents effective for the prevention or treatment of both ESGD and EGGD are therefore desirable.

A number of feed supplements for the treatment or prevention of EGUS have been evaluated (Andrews et al., 2016; Ferrucci et al., 2003; Hellings and Larsen, 2014; Huff et al., 2012; Murray and Grady, 2002; Sanz et al., 2014; Venner et al., 1999). Dietary phospholipids derived from soy, such as pectin and lecithin, have been used for amelioration of the effects of gastric or peptic ulceration in an number of species (Tovey et al., 2013), including horses (Andrews et al., 2016; Ferrucci et al., 2003; Murray and Grady 2002), and may exert their effect via reduced gastric acid secretion (Wang et al., 2011), mucosal protection (Tovey et al., 2013) or by alteration of gastric microbiota (Bai et al., 2016; Wang et al., 2011). Such products may be fermented or contain fermentative organisms such as Lactobacillus or Saccharomyces spp., with beneficial effects attributed to reduction in pathogenic bacteria, immunomodulatory effects or enhanced mucosal barrier integrity (GarciaHernandez et al., 2016; Khoder et al., 2016; Wang et al., 2011).

Fermaid ${ }^{\oplus}$ Ease 187 (Lallemand Australia Pty Ltd, Maroochydore, Australia; FE) is a nutritional supplement based on non-genetically modified micronised soya, fermented by Lactobacillus delbrueckii subspecies lactis Rosell - 187. The product is pasteurised and dried during the manufacturing process. The aim of the following study was to assess the effect of FE on horses with spontaneously occurring EGUS or those at risk for development of squamous or glandular mucosal ulceration. The hypothesis was that treatment with FE would be associated with significantly decreased gastric squamous and glandular mucosal ulcer scores.

\section{Materials and methods}

The study was approved by the Animal Care and Ethics Committee at CSU (ACEC, approval number 09/109), with the condition that owners could withdraw from the study at any time. Gastroscopy was performed on 120 horses presented to the Veterinary Clinical Centre at Charles Sturt University (CSU; Bathurst, Australia) between April 2010 and June 2011 using a $3 \mathrm{~m}$ endoscope $(9 \mathrm{~mm}$ outer diameter; Olympus Medical Systems Corporation, Tokyo, Japan; distributed via Austvet Endoscopy Pty Ltd, Mt Waverley, Victoria, Australia) using a 0-4 EGUS score, where 0 denoted no ulcers and 4 denoted severe, erosive and/or haemorrhagic ulcers (Andrews et al., 1999). Horses were evaluated at the university clinic or local training establishments, and were eligible for inclusion in the study if they exhibited squamous mucosal lesions of $\geq$ grade 1 and were continuing at the current intensity of work. Owners of horses with severe ESGD ( $\geq$ grade 3 ) were offered the option of omeprazole treatment, and these horses were excluded from participation in the study. Recruitment of study horses is shown in Figure 1.

Of the horses examined, 60 (50.0\%) were eligible for enrolment in the trial, with owners of 29 horses consenting to their inclusion in the study (Table 1). Of the remaining 31 horses with squamous or glandular lesions $\geq$ grade 1 , owners of ten horses declined further participation. One horse, referred for investigation of colic, was excluded from the study due to concerns that the ongoing diagnostic work up might confound treatment or results. A further 20 horses commenced period 1, but were withdrawn from the study before completion of the initial treatment period. This included ten horses that were spelled following flooding of their stables, one horse that was sold, one that was spelled due to injury, and one that died for reasons unrelated to the study. The owners or agents of the remaining seven horses did not give any reason for discontinuing treatment and were excluded due to concerns they had not complied with administration instructions or had failed to maintain the dietary treatment.

Feed was withheld for 12-14 h before gastroscopy and horses were sedated (xylazine $0.4 \mathrm{mg} / \mathrm{kg}$ IV and acetylpromazine $0.02 \mathrm{mg} / \mathrm{kg} \mathrm{IV}$ ) and appropriately restrained for gastroscopic examination. The stomach was gently inflated with air until distended such that gastric rugae were absent to enable observation of the non-glandular squamous mucosa, margo plicatus and glandular mucosa, including the pylorus. The mucosa was rinsed of adherent food material and mucus using tap water flushed through the endoscope biopsy channel. Each horse's stomach was assigned a score (Table 1) based on the established equine scoring system (Andrews et al., 1999) at the time of examination, but analysis of endoscopy findings was based on blinded evaluation of 


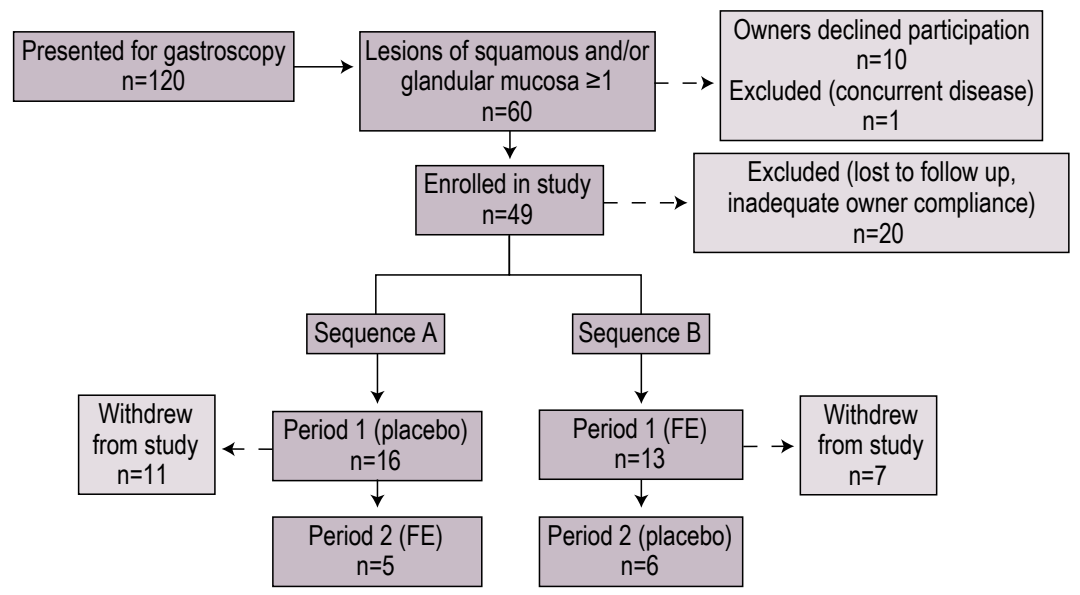

Figure 1. Recruitment of study horses. Of 120 horses presented for gastroscopic examination, 60 were considered eligible for inclusion in the study on the basis of squamous and/or glandular ulcer scores of $\geq 1$. Owners or agents of ten horses declined participation in the study, and one horse was excluded due to concurrent disease. Twenty horses failed to complete assigned treatment in period 1 due to injury, relocation or other factors, or due to inadequate compliance with treatment protocols. A further 18 horses withdrew from the study during period 2.

Table 1. Grading system for endoscopic assessment of squamous and glandular gastric mucosa (Andrews et al., 1999).

\begin{tabular}{|c|c|c|}
\hline & Squamous mucosa & Glandular mucosa \\
\hline Grade 0 & $\begin{array}{l}\text { The epithelium is intact and there is no appearance of hyperkeratosis } \\
\text { (yellowing of the mucosa) }\end{array}$ & The epithelium is intact and there is no evidence of hyperaemia \\
\hline Grade 1 & The mucosa is intact but there are areas of hyperkeratosis & The mucosa is intact but there are areas of hyperaemia \\
\hline Grade 2 & Small single or multifocal $(<5)$ superficial lesions & Small single or multifocal $(<5)$ focal superficial lesions \\
\hline Grade 3 & Large single deep or multiple $(\geq 5)$ focal superficial lesions & Large single deep or multiple $(\geq 5)$ focal superficial lesions \\
\hline Grade 4 & Extensive lesions with areas of apparent deep ulceration & Extensive lesions with areas of apparent deep ulceration \\
\hline
\end{tabular}

unidentified gastroscopy videos on completion of the study. A separate score was recorded for squamous and glandular lesions.

All participating horses were randomly assigned (by ballot) to receive either the FE treatment or placebo (an equivalent volume of ground pollard resembling the appearance and texture of FE) as the initial treatment. Horses recruited to the study continued their regular feeding and training programme for the duration of the study and owners were not permitted to administer medication for prevention or treatment of EGUS during the study. Owners or their agents received identical sealed plastic buckets containing product or placebo, and were responsible for administration of the assigned substance for 30 days, after which time endoscopy was performed. Owners or agents were blinded to treatments and asked to complete a treatment diary confirming daily administration as directed, noting adverse effects and overall impressions on horse health, and recording any additional medication administered to horses, as were the staff performing the gastroscopy. Horses with evidence of gastric ulceration $\geq$ grade 1 at the end of the initial 30 day treatment period were 'crossed over' on to the alternate product during period 2 of the study for a further 30 days. Sequence A (placebo then treatment with $25 \mathrm{~g}$ FE daily in feed) was administered to 16 horses and sequence B (treatment with $25 \mathrm{~g}$ FE daily in feed then placebo) to 13 horses. Five horses receiving sequence A completed both treatment periods, and six horses receiving sequence B completed both periods.

Scores for gastric ulceration on enrolment to the study were compared between horses allocated to sequence A or sequence B using the Mann Whitney test for both squamous and glandular lesions. Pre-treatment (d 0) gastroscopy findings were compared with post-treatment (d 31) findings by the Wilcoxon matched-pairs signed rank test, with separate analyses for period 1 and period 2. Response to treatment (placebo vs FE) was assessed by the Mann Whitney test using pooled data from both treatment periods. The percentage of horses demonstrating increased gastric squamous ulcer scores following FE or placebo treatment in either period was compared by Fisher's exact test. In all instances, $P<0.05$ was considered significant. 


\section{Results}

Results of all treatment or placebo interventions are presented in Table 2. All horses reportedly found both placebo and FE palatable, and no adverse effects attributable to FE administration were observed during the study. As evident in Table 2, study horses were predominantly Thoroughbred $(n=20)$ or Standardbred $(n=7)$ horses in race work $(n=23)$, with six horses used for performance disciplines, including one Warmblood-Thoroughbred cross and one Arab. Study horses ranged in age from 2 to 22 years, and 18 were geldings, ten were female. Of the 16 horses assigned to sequence $A$, owners or trainers reported vague clinical signs (inappetence and/or difficulty maintaining condition) for four. Three (of 13) sequence B horses had similar observations noted prior to treatment. There was no difference $(P=0.102)$ between median gastric squamous ulcer score on enrolment to the study for horses receiving sequence A $(2,95 \%$ CI $2-2)$ or sequence B (2, 95\% CI $2-3)$. Similarly, median ulcer scores for glandular lesions on commencing the study were not different $(P=0.110)$ between sequences (sequence A, 1, 95\% CI 0 - 2; sequence
B, 0, 95\% CI 0 - 1). One sequence A horse was excluded after period 1 due to non-compliant behaviour, one died of unrelated causes during period 2, five were spelled before completing period 2 and four horses were removed without any explanation from owners or agents. One sequence B horse was spelled prior to completing period 2, one was withdrawn from the study because the owner felt his condition so much improved there was no need for ongoing treatment, and five sequence B horses failed to complete period 2 for reasons that were not disclosed.

Supplementation with FE was associated with a significant reduction in squamous ulcer scores at $\mathrm{d} 31$ when compared to d 0 in period $1(P=0.008$, Figure 2). Median (95\% CI) squamous ulcer score on Day 0 for FE treated horses was 2 (2-3); following treatment the median score was 1 (1-2). A similar effect was observed in period 2 , however the observed difference was not significant $(P=0.125)$ due to the smaller numbers of horses in this cohort. In contrast, squamous scores for horses receiving placebo treatment were unchanged $(P=1.000)$ in period 1 , and tended to increase $(P=0.062)$ in period 2 (Figure 2 ).

Table 2. Details of breed, gender and age for $\mathbf{2 9}$ study horses. Horses in the same stable are indicated by superscript. Gastroscopy lesion scores are shown at the commencement of the study, after treatment period 1 and, if applicable, after treatment period 2.

\begin{tabular}{|c|c|c|c|c|c|c|c|c|c|c|c|c|c|}
\hline \multirow[t]{2}{*}{$\begin{array}{l}\text { Horse } \\
\text { number }\end{array}$} & \multirow[t]{2}{*}{ Breed $^{1}$} & \multirow[t]{2}{*}{ Gender } & \multirow[t]{2}{*}{$\begin{array}{l}\text { Age } \\
\text { (years) }\end{array}$} & \multirow[t]{2}{*}{ Purpose } & \multirow[t]{2}{*}{ Examination } & \multicolumn{2}{|c|}{$\begin{array}{l}\text { Gastroscopy } \\
\text { pre-tx }{ }^{2}\end{array}$} & \multirow[t]{2}{*}{$\begin{array}{l}\text { Treatment } \\
\text { period } 1^{3}\end{array}$} & \multicolumn{2}{|c|}{$\begin{array}{l}\text { Gastroscopy } \\
\text { post-tx period } 1\end{array}$} & \multirow[t]{2}{*}{$\begin{array}{l}\text { Treatment } \\
\text { period } 2\end{array}$} & \multicolumn{2}{|c|}{$\begin{array}{l}\text { Gastroscopy } \\
\text { post-tx period } 2\end{array}$} \\
\hline & & & & & & Sqm & Gld & & Sqm & Gld & & Sqm & Gld \\
\hline \multicolumn{14}{|l|}{ Sequence $A$} \\
\hline P004 & TB & Geld & 9 & Performance & At clinic & 2 & 0 & $\mathrm{Pl}$ & 1 & 0 & & & \\
\hline P010 & TB & Geld & 6 & Race work & At stable & 2 & 1 & PI & 2 & 0 & FE & 2 & 0 \\
\hline$P 015^{a}$ & TB & Geld & 6 & Race work & At stable & 2 & 0 & $\mathrm{Pl}$ & 3 & 0 & FE & 1 & 1 \\
\hline $\mathrm{P} 024^{\mathrm{a}}$ & TB & Filly & 2 & Race work & At stable & 2 & 1 & $\mathrm{Pl}$ & 2 & 1 & & & \\
\hline$P 025^{a}$ & TB & Mare & 4 & Race work & At stable & 2 & 0 & $\mathrm{Pl}$ & 3 & 1 & & & \\
\hline$P 035^{d}$ & TB & Geld & 3 & Race work & At stable & 3 & 2 & $\mathrm{Pl}$ & 2 & 0 & FE & 1 & 0 \\
\hline$P 036^{d}$ & TB & Geld & 2 & Race work & At stable & 2 & 1 & $\mathrm{PI}$ & 2 & 1 & & & \\
\hline $\mathrm{P} 037^{d}$ & TB & Mare & 7 & Race work & At stable & 2 & 0 & $\mathrm{Pl}$ & 2 & 0 & & & \\
\hline P040a & SB & Geld & 6 & Race work & At clinic & 3 & 1 & $\mathrm{PI}$ & 3 & 2 & & & \\
\hline P058 & SB & Geld & 4 & Race work & At stable & 1 & 1 & $\mathrm{Pl}$ & 1 & 1 & & & \\
\hline $\mathrm{P} 080^{\mathrm{e}}$ & SB & Geld & 8 & Race work & At stable & 2 & 2 & $\mathrm{PI}$ & 1 & 0 & & & \\
\hline P085 & TB & Mare & 5 & Performance & At clinic & 2 & 1 & $\mathrm{Pl}$ & 2 & 1 & FE & 0 & 0 \\
\hline P095 & Arab & Geld & 22 & Performance & At clinic & 1 & 1 & $\mathrm{Pl}$ & 2 & 1 & & & \\
\hline P112 & WB $X$ & Geld & 6 & Performance & At clinic & 1 & 1 & $\mathrm{Pl}$ & 1 & 2 & & & \\
\hline \multicolumn{14}{|c|}{ Sequence B } \\
\hline P005 & TB & Geld & 5 & Performance & At clinic & 3 & 0 & FE & 1 & 0 & $\mathrm{PI}$ & 3 & 0 \\
\hline P007 & TB & Mare & 6 & Race work & At stables & 2 & 0 & $\mathrm{FE}$ & 1 & 1 & $\mathrm{PI}$ & 2 & 0 \\
\hline $\mathrm{P} 011^{\mathrm{a}}$ & TB & Mare & 4 & Race work & At stables & 3 & 1 & FE & 3 & 1 & & & \\
\hline$P 013^{a}$ & TB & Geld & 6 & Race work & At stables & 3 & 1 & FE & 3 & 1 & $\mathrm{Pl}$ & 3 & 1 \\
\hline$P 021^{b}$ & TB & Geld & 10 & Race work & At stables & 2 & 1 & $\mathrm{FE}$ & 2 & 0 & & & \\
\hline $\mathrm{P} 022^{\mathrm{b}}$ & TB & Mare & 4 & Race work & At stables & 2 & 0 & FE & 2 & 0 & & & \\
\hline $\mathrm{P} 030^{\circ}$ & SB & Geld & 4 & Race work & At stables & 2 & 0 & $\mathrm{FE}$ & 2 & 1 & & & \\
\hline $\mathrm{P} 032^{\mathrm{C}}$ & TB & Mare & 5 & Race work & At stables & 2 & 0 & FE & 1 & 0 & $\mathrm{Pl}$ & 3 & 0 \\
\hline$P 033^{d}$ & TB & Geld & 3 & Race work & At stables & 3 & 2 & FE & 1 & 0 & $\mathrm{PI}$ & 2 & 0 \\
\hline P039a & TB & Geld & 5 & Race work & At stables & 2 & 0 & $\mathrm{FE}$ & 1 & 0 & & & \\
\hline P078e & SB & Geld & 3 & Race work & At stables & 4 & 0 & FE & 2 & 0 & & & \\
\hline P084 & SB & Filly & 2 & Race work & At stables & 2 & 1 & FE & 1 & 1 & $\mathrm{Pl}$ & 3 & 2 \\
\hline P099 & TB & Mare & 10 & Performance & At clinic & 2 & 1 & FE & 1 & 1 & & & \\
\hline
\end{tabular}

1 SB = Standardbred; TB = Thoroughbred; WB X = Warmblood - TB cross.

${ }^{2} \mathrm{Gld}=$ glandular ulcer score; Sqm = squamous ulcer score.

${ }^{3} \mathrm{FE}=$ FermaidEase; $\mathrm{PI}=$ placebo 
A

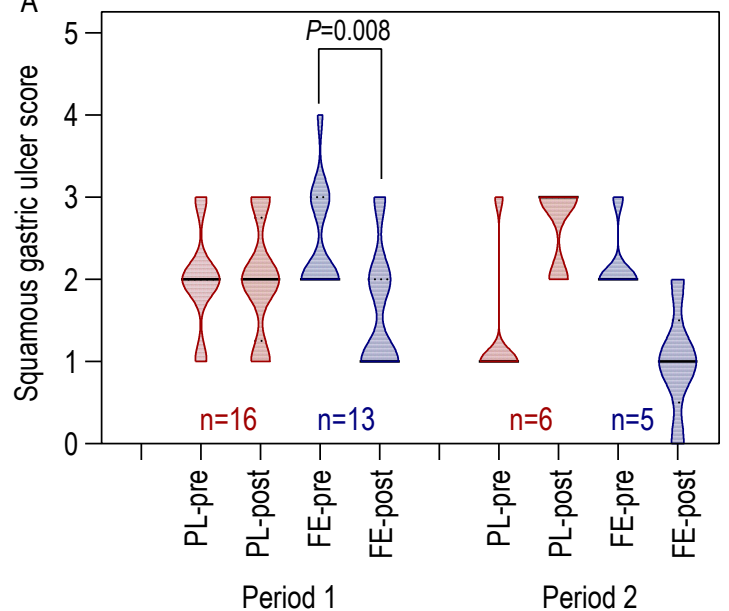

B

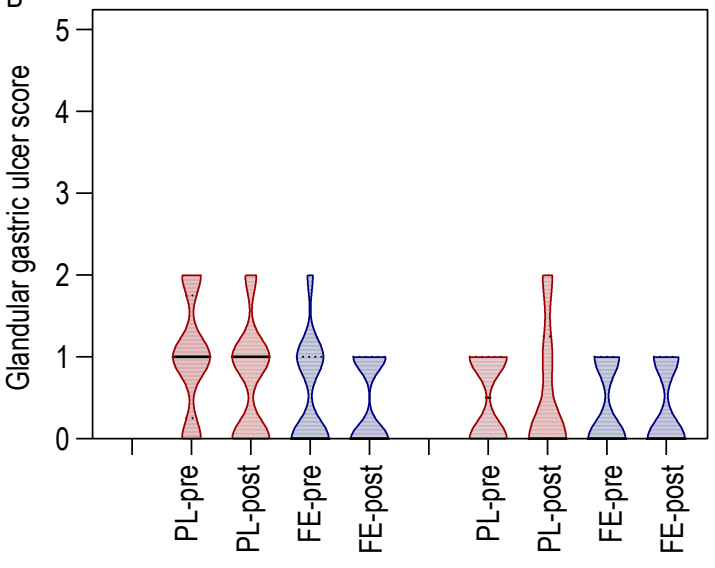

Period 1

Period 2

Figure 2. Effect of supplementation with placebo (red, PL) or FermaidEase (blue, FE) on (A) gastric squamous and (B) glandular mucosal ulcer scores during treatment periods 1 and 2. Results on day 0 (pre) were compared with endoscopy findings on Day 31 (post), after 30 days treatment, by Wilcoxson matched pairs signed rank test. Data are shown as violin plots with median (solid line) and inter-quartile range (dashed line) indicated, and with the number of horses in each group ( $n$ ) shown for squamous results.

Pooled data from both treatment periods showed that sixteen horses (of 22; 72.7\%) still had medium to severe ( $\geq$ grade 2 ) squamous ulceration following the placebo treatment, and seven horses (31.8\%) had more severe ulceration than on $\mathrm{d} 0$. By contrast, seven horses receiving FE (of $18,38.9 \%$ ) had $\geq$ grade 2 squamous ulcer scores and no horse exhibited increased gastric squamous ulcer scores after FE treatment. The proportion of horses with increased gastric squamous scores was greater following placebo treatment than following $\mathrm{FE}(P=0.011)$. Squamous scores on $\mathrm{d} 31$ were lower for horses receiving FE than the placebo in either sequence $(P=0.005$, Figure 3$)$.

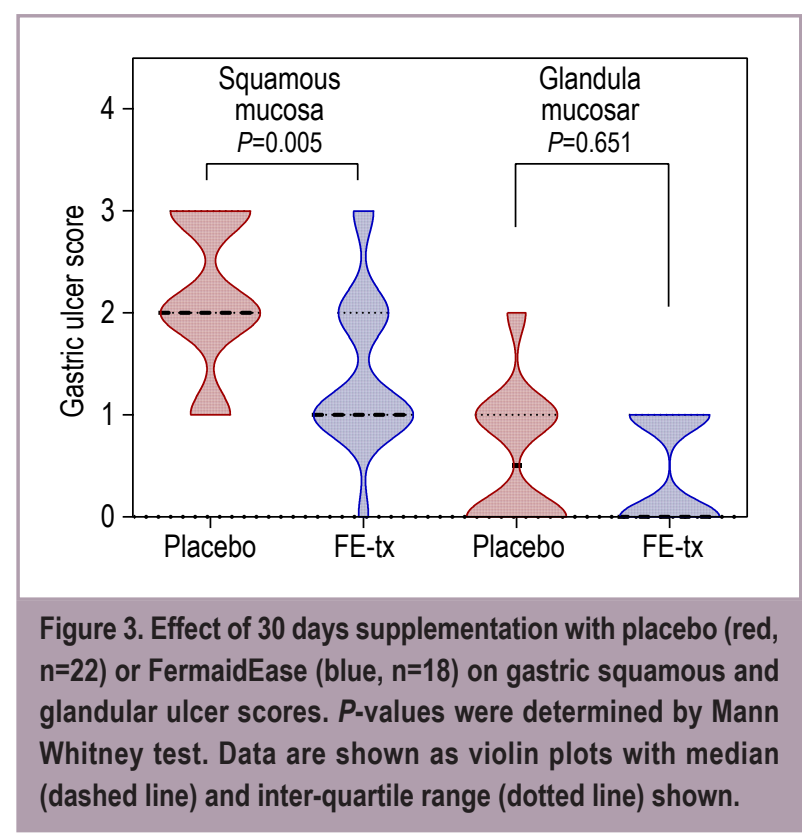

No effect was observed on glandular scores associated with administration of placebo $(P=0.367$, period 1; $P=1.000$, period 2) or FE ( $P=1.000$, period 1; $P=1.000$, period 2; Figure 2) and there was no difference between glandular scores on $\mathrm{d} 31$ between the placebo or FE treated horses when pooled treatment responses were compared on $\mathrm{d} 31$ $(P=0.651$, Figure 3$)$.

\section{Discussion}

The current study demonstrated a significant reduction in squamous gastric ulcer scores associated with 30 days supplementation with FE in period $1(\mathrm{n}=13)$. A similar, but not significant, effect was observed in period 2. By contrast, squamous ulcer scores were unchanged for horsed fed the placebo in period $1(n=19)$. For sequence A horses, squamous scores increased during the treatment with the placebo in period 2, and this effect approached significance. The small number of horses retained in period 2 limited the capacity to generate statistically significant results associated with the reciprocal treatment. As recruited horses were either in racing or performance work, placebo-treated horses demonstrated unchanged or increased squamous ulcer scores as management factors predisposing them to the development or progression of gastric squamous mucosal ulceration (Sykes and Jokisalo, 2015b), including stabling, intermittent feeding, concentrate diets and exercise, were ongoing during the study. No treatment effects were observed for glandular ulcer scores.

Consistent with the vague and non-specific clinical effects of EGUS and the relatively mild condition of some horses recruited to the study, few clinical signs associated with 
EGUS were reported by owners or agents for affected horses. Consequently, subjective external observations of improvement during FE treatment were reported for only three horses. However, no horse receiving placebo was considered to be improved and, in fact, carers observed that four horses receiving placebo treatment has lower feed intake and were less alert than at the start of the study, or when receiving FE. Objective measures of well-being, such as body weight, were not measured in the current study, but carers were asked to record the amount of feed left, monitor faecal output and to diarise any subjective impressions of health in an attempt to ensure contemporaneous recording of such observations.

The beneficial effect observed in the current study might have been attributable to dietary components of the supplement or due to the effects of fermentative bacteria. Three barriers have been identified in defence of mucosal integrity of the monogastric stomach (Laine et al., 2008). Within the gastric lumen, a mucus-bicarbonatephospholipid layer forms the pre-epithelial barrier. This layer has been recognised in horses (Ethell et al., 2000), and is particularly important in the glandular stomach. The epithelial barrier is maintained by cellular restitution, which is affected by high epithelial cell turnover, tight junctions and secretory products, including prostaglandins, trefoil factors and heat shock proteins (Khoder et al., 2016). The sub-epithelial capillary network defines the final barrier, supporting cell growth and secretory functions, and is regulated by prostaglandins, nitric oxide, hydrogen sulphide and sensory innervations (Laine et al., 2008). The effect of FE administration on gastric ulceration might be due to enhanced barrier function at any of these levels, or may have been due to decreased gastric acid secretion (Wang et al., 2011) or immunomodulatory effects (Easo et al., 2002, Garcia-Hernandez et al., 2016, Shokryazdan et al., 2016).

Dietary soy has been associated with decreased incidence of gastric ulceration in people (Tovey et al., 2013), a finding attributed to the presence of lipid, phospholipid and sterol fractions (Tovey 2015; Tovey et al., 2013), including lecithin and pectin. A number of equine studies have evaluated the effect of supplements containing lecithin and pectin (Andrews et al., 2016; Ferrucci et al., 2003; Murray and Grady, 2002; Sanz et al., 2014; Venner et al., 1999). Prospective studies of spontaneous disease (Ferrucci et al., 2003; Venner et al., 1999) have demonstrated a positive effect on gastric ulceration in horses, as observed in the current study, whereas studies based on experimental induction of disease have failed to demonstrate an effect (Murray and Grady, 2002; Sanz et al., 2014). The administration of lactic acid bacteria, such as Lactobacillus and Bifidobacterium spp., as viable or killed organisms has been associated with beneficial effects on gastric ulceration (Khoder et al., 2016) including suppression of pathogenic bacteria (Garcia-Hernandez et al., 2016), although there is no evidence supporting pathogenic bacteria in the aetiology of EGUS (Al Jassim and Andrews, 2009; Dong et al., 2016). Hence, directly or indirectly, the administration of soy and/ or fermentative bacteria may influence mucosal immunity (Adachi et al., 2011; Easo et al., 2002; Garcia-Hernandez et al., 2016; Ko et al., 2009; Laino et al., 2016; Singh and Kaur, 2012; Singh et al., 2012; Wallace et al., 2003) and healing (Adachi et al., 2011; Singh et al., 2012).

Randomised prospective, double-blind, placebo-controlled trials, such as reported here, represent strong experimental design for evaluating treatment of spontaneous disease. However, efficacy may have been compromised by a number of factors evident in the current study. Firstly, treatments were administered by owners or their agents. Although carers for horses in this study were required to keep a treatment diary, and horses where owner compliance was questionable were excluded, it was not possible to guarantee that treatment was administered as directed. The placebo (pollard) and FE were dispensed in identical, sealed plastic buckets but not inspected by staff conducting endoscopic examination. Participants were blinded as to which treatment their horse was receiving, however, the more astute might have been able to differentiate the placebo from product, as pollard is a common feed component in some stables. Although this was not communicated to staff performing endoscopy, it may have influenced subjective evaluations during the treatment period.

The most notable limitation of the current study was the relative difficulty in recruiting and retaining horses for the second period of each sequence. Future randomised controlled trials should recruit a study population much greater than the number required to ensure sufficient statistical power. Alternatively, greater incentives to commit to the study completion, or greater control over horse movements within the study population, might protect outcomes. The study population of 29 horses in the current study, with 11 horses completing both treatment periods, was equivalent or greater than similar studies evaluating feed supplements in horses with spontaneous disease $(n=10$ Ferrucci et al., 2003; n=24 Venner et al., 1999; Sykes et al., 2014) and involved gastroscopic assessment of 120 horses. The overall prevalence of EGUS in horses presented for examination (50\%), based on the observation of squamous mucosal lesions of $\geq$ grade 1 , was consistent with, or lower than, reports in similar populations (Begg and O'Sullivan, 2003; Luthersson et al., 2009; McClure et al., 2016; Roy et al., 2005; Tamzali et al., 2011), despite a recruitment protocol that might have been expected to exert a positive selection bias. Hence, 60 horses were eligible for inclusion, and 31 of these horses were not enrolled into the study at the request of owners, which was a condition of ethical approval, or were removed due to changed circumstances or concerns about non-compliance with study requirements. The majority of horses did not cross over to complete period 
2 of their assigned treatment sequence, further reflecting difficulties in retaining client owned horses for a protracted (60 day) interventional study.

The study included animals with mild squamous lesions (grade 1), that might not be associated with clinical disease. The inclusion of animals with mild disease might have been expected to limit our ability to discriminate a treatment effect. However, a beneficial effect was observed with administration of FE to horses experiencing or at risk for ESGD. No effect was observed on glandular ulcer scores, which might reflect the number of horses with mild or no glandular ulceration at the commencement of the study, or differences in the pathophysiology of glandular lesions (Sykes and Jokisalo, 2015a).

\section{Conclusions}

These findings supported the use of FE in horses predisposed to ulceration of the gastric squamous mucosa and suggested that FE may be a promising, nonpharmaceutical product for treatment or prevention of EGUS in racing and performance horses.

\section{Acknowledgements}

The authors thank Rebekah West, Dr Caroline Foote and Dr Susan Armstrong for assistance with gastroscopy and communication with study participants.

\section{Conflict of interest}

The authors declare that no conflict of interests exists.

\section{Funding}

This study was funded by Probiotec Limited. Probiotec supplied product and placebo in identical packaging for use in the study, but did not influence experimental design, conduct or interpretation of results. Lallemand Australia have contributed to agistment costs for teaching horses at Charles Sturt University subsequent to completion of this study.

\section{References}

Adachi, M., Horiuchi, G., Ikematsu, N., Tanaka, T., Terao, J., Satouchi, K. and Tokumura, A., 2011. Intragastrically administered lysophosphatidic acids protect against gastric ulcer in rats under water-immersion restraint stress. Digestive Diseases and Sciences 56: 2252-2261.

Al Jassim, R.A. and Andrews, F.M., 2009. The bacterial community of the horse gastrointestinal tract and its relation to fermentative acidosis, laminitis, colic, and stomach ulcers. The Veterinary Clinics of North America Equine Practice 25: 199-215.
Andrews, F., Bernard, W., Byars, D., Cohen, N., Divers, T., MacAllister, C., McGladdery, A., Merritt, A.M., Murray, M.J., Orsini, J., Snyder, J. and Vatistas, N., 1999. Recommendations for the diagnosis and treatment of equine gastric ulcer syndrome (EGUS). Equine Veterinary Education 11: 262-272

Andrews, F.M., Camacho-Luna, P., Loftin, P.G., Gaymon, G., Garza, F., Keowen, M.L. and Kearney, M.T., 2016. Effect of a pelleted supplement fed during and after omeprazole treatment on nonglandular gastric ulcer scores and gastric juice $\mathrm{pH}$ in horses. Equine Veterinary Education 28: 196-202.

Andrews, F.M., Frank, N., Sommardahl, C.S., Buchanan, B.R., Elliott, S.B. and Allen, V.A., 2006. Effects of intravenously administrated omeprazole on gastric juice $\mathrm{pH}$ and gastric ulcer scores in adult horses. Journal of Veterinary Internal Medicine 20: 1202-1206.

Bai, G., Ni, K., Tsuruta, T. and Nishino, N., 2016. Dietary casein and soy protein isolate modulate the effects of raffinose and fructooligosaccharides on the composition and fermentation of gut microbiota in rats. Journal of Food Science 81: H2093-H2098.

Begg, L.M. and O'Sullivan, C.B., 2003. The prevalence and distribution of gastric ulceration in 345 racehorses. Australian Veterinary Journal 81: 199-201.

Dong, H.J., Ho, H., Hwang, H., Kim, Y., Han, J., Lee, I. and Cho, S., 2016. Diversity of the gastric microbiota in Thoroughbred racehorses having gastric ulcer. Journal of Microbiology and Biotechnology 26: 763-774.

Easo, J.G., Measham, J.D., Munroe, J. and Green-Johnson, J.M., 2002. Immunostimulatory actions of lactobacilli: mitogenic induction of antibodiy productoin and spleen cell proliferation by Lactobacillus delbrueckii subsp bulgaricus and Lactobacillus acidophilus. Food and Agricultural Immunology 14: 73-83.

Ethell, M.T., Hodgson, D.R. and Hills, B.A., 2000. Evidence for surfactant contributing to the gastric mucosal barrier of the horse. Equine Veterinary Journal 32: 470-474.

Ferrucci, F., Zucca, E., Croci, C., Di Fabio, V. and Ferro, E., 2003. Treatment of gastric ulceration in 10 standardbred racehorses with a pectin-lecithin complex. Veterinary Record 152: 679-681.

Garcia-Hernandez, Y., Perez-Sanchez, T., Boucourt, R., Balcazar, J.L., Nicoli, J.R., Moreira-Silva, J., Rodriguez, Z., Fuertes, H., Nunez, O. and Albelo N., 2016. Isolation, characterization and evaluation of probiotic lactic acid bacteria for potential use in animal production. Research in Veterinary Science 108: 125-132.

Hartmann A.M. and Frankeny, R.L., 2003. A preliminary investigation into the association between competition and gastric ulcer formation in non-racing performance horses. Journal of Equine Veterinary Science 23: 560-561.

Hellings, I.R. and Larsen, S., 2014. ImproWin((R)) in the treatment of gastric ulceration of the squamous mucosa in trotting racehorses. Acta Veterinaria Scandinavica 56(1): 13.

Huff, N.K., Auer, A.D., Garza Jr, F., Keowen, M.L., Kearney, M.T., McMullin, R.B. and Andrews, F.M., 2012. Effect of sea buckthorn berries and pulp in a liquid emulsion on gastric ulcer scores and gastric juice $\mathrm{pH}$ in horses. Journal of Veterinary Internal Medicine 26: 1186-1191. 
Jackson, M.A., Goodrich, J.K., Maxan, M.E., Freedberg, D.E., Abrams, J.A., Poole, A.C., Sutter, J.L., Welter, D., Ley, R.E. and Bell, J.T., 2016. Proton pump inhibitors alter the composition of the gut microbiota. Gut 65: 749-756.

Khoder, G., Al-Menhali, A.A., Al-Yassir, F. and Karam, S.M., 2016. Potential role of probiotics in the management of gastric ulcer. Experimental and Therapeutic Medicine 12: 3-17.

Ko, K.P., Park, S.K., Cho, L.Y., Gwack, J., Yang, J.J., Shin, A., Kim, C.S., Kim, Y., Kang, D. and Chang, S.H., 2009. Soybean product intake modifies the association between interleukin-10 genetic polymorphisms and gastric cancer risk. The Journal of Nutrition 139: 1008-1012.

Laine, L., Takeuchi, K. and Tarnawski, A., 2008. Gastric mucosal defense and cytoprotection: bench to bedside. Gastroenterology 135: 41-60.

Laino, J., Villena, J., Kanmani, P. and Kitazawa, H., 2016. Immunoregulatory effects triggered by lactic acid bacteria exopolysaccharides: new insights into molecular interactions with host cells. Microorganisms 4: 27.

le Jeune, S.S., Nieto, J.E., Dechant, J.E. and Snyder, J.R., 2009. Prevalence of gastric ulcers in Thoroughbred broodmares in pasture: a preliminary report. Veterinary Journal 181: 251-255.

Lester, G.D., Robertson, I and Secombe, C., 2008. Risk factors for gastric ulceration in Thoroughbred racehorses. RIRDC publication 08/061. Rural Industries Research and Development Corporation, Murdoch, WA, Australia. Available at: https://tinyurl.com/yd6x3u6m.

Luthersson, N., Nielsen, K.H., Harris, P. and Parkin, T.D. 2009. Risk factors associated with equine gastric ulceration syndrome (EGUS) in 201 horses in Denmark. Equine Veterinary Journal 41: 625-630.

Malmkvist, J., Poulsen, J.M., Luthersson, N., Palme, R., Christensen, J.W. and Sondergaard, E., 2012. Behaviour and stress responses in horses with gastric ulceration. Applied Animal Behaviour Science 142: 160-167.

McClure, S.R., Campbell, J., Polo, J. and Lognion, A., 2016. The effect of serum-based bioactive proteins for the prevention of squamous gastric ulcers in horses. Journal of Equine Veterinary Science 43: 32-38.

McClure, S.R., Glickman, L.T. and Glickman, N.W., 1999. Prevalence of gastric ulcers in show horses. Journal of the American Veterinary Medical Association 215: 1130-1133.

Murray, M.J. and Grady, T.C., 2002. The effect of a pectin-lecithin complex on prevention of gastric mucosal lesions induced by feed deprivation in ponies. Equine Veterinary Journal., 34: 195-198.

Murray, M.J., Schusser, G.R.F., Pipers, F.S. and Gross, S.J., 1996. Factors associated with gastric lesions in thoroughbred racehorses. Equine Veterinary Journal 28: 368-374.

Nadeau, J.A., Andrews, F.M., Patton, C.S., Argenzio, R.A., Mathew, A.G. and Saxton, A.M., 2003a. Effects of hydrochloric, acetic, butyric, and propionic acids on pathogenesis of ulcers in the nonglandular portion of the stomach of horses. American Journal of Veterinary Research 64: 404-412.

Nadeau, J.A., Andrews, F.M., Patton, C.S., Argenzio, R.A., Mathew, A.G. and Saxton, A.M., 2003b. Effects of hydrochloric, valeric, and other volatile fatty acids on pathogenesis of ulcers in the nonglandular portion of the stomach of horses. American Journal of Veterinary Research 64: 413-417.
Nicol, C.J., Davidson, H.P.D., Harris, P.A., Waters, A.J. and Wilson, A.D., 2002. Study of crib-biting and gastric inflammation and ulceration in young horses. Veterinary Record 151: 658-662.

Orsini, J.A., Haddock, M., Stine, L., Sullivan, E.K., Rabuffo, T.S. and Smith, G., 2003. Odds of moderate or severe gastric ulceration in racehorses receiving antiulcer medications. Journal of the American Veterinary Medical Association 223: 336-339.

Roy, M.A., Vrins, A., Beauchamp, G. and Doucet, M.Y., 2005. Prevalence of ulcers of the squamous gastric mucosa in Standardbred horses. Journal of Veterinary Internal Medicine. 19: 744-750.

Sanz, M.G., Viljoen, A., Saulez, M.N., Olorunju, S. and Andrews, F.M., 2014. Efficacy of a pectin-lecithin complex for treatment and prevention of gastric ulcers in horses. Veterinary Record 175: 147.

Shokryazdan, P., Faseleh Jahromi, M., Navidshad, B. and Liang, J.B., 2016. Effects of prebiotics on immune system and cytokine expression. Medical Microbiology and Immunology 206: 1-9.

Singh, P.K. and Kaur, I.P., 2012. Synbiotic (probiotic and ginger extract) loaded floating beads: a novel therapeutic option in an experimental paradigm of gastric ulcer. The Journal of Pharmacy and Pharmacology 64: 207-217.

Singh, P.K., Deol, P.K. and Kaur, I.P., 2012. Entrapment of Lactobacillus acidophilus into alginate beads for the effective treatment of cold restraint stress induced gastric ulcer. Food and Function 3: 83-90.

Stothert, J.C., Jr., Simonowitz, D.A., Dellinger, E.P., Farley, M., Edwards, W.A., Blair, A.D., Cutler, R. and Carrico, C.J., 1980. Randomized prospective evaluation of cimetidine and antacid control of gastric $\mathrm{pH}$ in the critically ill. Annals of Surgery 192: 169-174.

Sykes, B.W. and Jokisalo, J.M., 2014. Rethinking equine gastric ulcer syndrome: Part 1 - Terminology, clinical signs and diagnosis. Equine Veterinary Education 26: 543-547.

Sykes, B. and Jokisalo, J.M., 2015a. Rethinking equine gastric ulcer syndrome: Part 3 - Equine glandular gastric ulcer syndrome (EGGUS). Equine Veterinary Education. 27: 372-375.

Sykes, B.W. and Jokisalo, J.M., 2015b. Rethinking equine gastric ulcer syndrome: Part 2 - Equine squamous gastric ulcer syndrome (ESGUS). Equine Veterinary Education 27: 264-268.

Sykes, B.W., Hewetson, M., Hepburn, R.J., Luthersson, N. and Tamzali, Y., 2015. European College of Equine Internal Medicine Consensus Statement - Equine gastric ulcer syndrome in adult horses. Journal of the American Veterinary Medical Association 29: 1288-1299.

Sykes, B.W., Sykes, K.M. and Hallowell, G.D., 2014. Efficacy of a combination of Apolectol, live yeast (Saccharomyces cerevisiae [CNCM I-1077]), and magnesium hydroxide in the managment of equine gastric ulcer syndrome in Thoroughbred raceshorses: a blinded, randomised, placebo controlled clinical trial. Journal of Equine Veterinary Science 34: 1274-1278.

Tamzali, Y., Marguet, C., Priymenko, N. and Lyazrhi, F., 2011. Prevalence of gastric ulcer syndrome in high-level endurance horses. Equine Veterinary Journal 43: 141-144.

Tovey, F.I., 2015. Role of dietary phospholipids and phytosterols in protection against peptic ulceration as shown by experiments on rats. World Journal of Gastroenterology 21: 1377-1384.

Tovey, F.I., Bardhan, K.D. and Hobsley, M., 2013. Dietary phosphilipids and sterols protective against peptic ulceration. Phytotherapy Research 27: 1265-1269. 
Venner, M., Lauffs, S. and Deegen, E., 1999. Treatment of gastric lesions in horses with pectin-lecithin complex. Equine Veterinary Journal, Supplement. 31(S29): 91-96.

Videla, R. and Andrews, F.M., 2009. New perspectives in equine gastric ulcer syndrome. Veterinary Clinics of North America - Equine Practice 25: 283-301.
Wallace, T.D., Bradley, S., Buckley, N.D. and Green-Johnson, J.M., 2003. Interactions of lactic acid bsacteria with human intestinal epithelial cells: effects on cytokine production. Journal of Food Protection 66: 466-472.

Wang, H.E., Chang, C.H., Ker, Y.B., Peng, C.C., Chen, K.C. and Peng, R.Y., 2011. Fermented soybean liquid alleviated peptic ulcer through the destruction of acidic proton pump rather than suppression of urease of Helicobacter pylori: a kinetic analysis. Journal of Agricultural and Food Chemistry 59: 6730-6739. 
